\title{
Current Experimental Therapy for Alzheimer's Disease
}

\author{
Sheng Chen ${ }^{\mathrm{a}}$, Xiao-Jie Zhang ${ }^{\mathrm{b}}$, Liang $\mathrm{Li}^{\mathrm{b}}$ and Wei-Dong Le $\mathrm{e}^{\mathrm{a}, \mathrm{b}, *}$ \\ ${ }^{a}$ Institutes of Neurology, Ruijin Hospital, Jiao Tong University School of Medicine, Shanghai, China; ${ }^{b}$ Laboratory of Neurogenomics, \\ Institute of Health Sciences, Shanghai Institutes for Biological Sciences, Chinese Academy of Sciences
}

\begin{abstract}
In the past decade, enormous efforts have been devoted to understand the genetics and molecular pathogenesis of Alzheimer's disease (AD), which has been transferred into extensive experimental approaches aimed at reversing disease progression. The trend in future $\mathrm{AD}$ therapy has been shifted from traditional anti-acetylcholinesterase treatment to multiple mechanisms-based therapy targeting amyloid plaques formation and amyloid peptides $(\mathrm{A} \beta)$-mediated cytotoxicity, and neurofibrillary tangles generation. This review will cover current experimental studies with the focus on secretases-based drug development, immunotherapy, and anti-neurofibrillary tangles intervention. The outcome of these on-going studies may provide high hope that $\mathrm{AD}$ can be cured in the future.
\end{abstract}

Key Words: Experimental approach, Alzheimer's disease, secretase, amyloid plaque, neurofibrillary tangles, immunotherapy, small interfering molecule, gene therapy.

\section{INTRODUCTION}

Alzheimer's disease (AD) is the most common cause of dementia characterized by progressive cognitive impairment in the elderly people. According to the World Health Organization, it is estimated that $50 \%$ of people older than age 85 years are afflicted with AD. Neurofibrillary tangles comprising hyperphosphorylated tau proteins and neuritic amyloid plaques represent the core neuropathologic features of AD [20]. Although cholinesterase inhibitors including tacrine, donepezil and galantamine have been used for symptomatic treatment of patients with $\mathrm{AD}$, these conventional treatments fail to postpone the progression of the disease $[30,65$, 70]. The ideal therapies for AD should be not only effectively improving the dementia symptoms but also fundamentally reducing the burden of senile plaques and neurofibrillary tangles and thus protect the neurons from degeneration. Currently several drugs and agents that either affect secretory amyloid precursor degradation, or inhibit amyloid peptides aggregation or block hyperphosphorylated tau protein formation are under investigation in preclinical trials. While the perspective of other therapies such as immunotherapy, anti-apoptotic therapy and anti-inflammatory therapy remain blurred for the uncertainty of whether they can be used in human beings as safely and effectively as in animals. These new approaches are representatives of current therapeutic development for the treatment of $\mathrm{AD}$.

\section{APPROACHES AIMED AT A $\beta$ GENERATION AND DEG- RADATION}

In normal process, amyloid precursor protein (APP) is cleaved by $\alpha$-secretase to release a large, soluble ectodomain fragment (soluble $\mathrm{APP} \alpha[\mathrm{s} \mathrm{APP} \alpha]$ ), leaving a $\mathrm{C}$-terminal fragment of 83 amino acids (C83) which can undergo secondary cleavage by the $\gamma$ secretase to generate a small peptide that makes up the latter two thirds of the $\beta$-amyloid protein region (p3). APP can also undergo abnormal cleavage processing at the amino terminus of $A \beta$ by a membrane-bound aspartyl protease ( $\beta$-secretase), generating a large secreted derivative (soluble APP $\beta$ [sAPP $\beta]$ ) and a membrane-bound $\beta$-cleaved carboxy terminal fragment (CTF $\beta$; also known as C99). Cleavage of CTF $\beta$ by $\gamma$-secretase results in the production of the $A \beta 40$ and $A \beta 42$ species, the latter of which is prone to aggregation $[20,81]$. Two genes in which mutations are associated with early onset familial AD have been identified as Presenilin 1 (PS1) on chromosome 14 and Presenilin 2 (PS2) on chromosome 1 [17]. Mutations in PS1 and PS2 lead to an excessive A $\beta 42$ peptide deposition in the neurons [90]. Intracellular $A \beta 42$ peptide accumulation is demonstrated to initiate $A \beta$-peptide cascades causing free radical generation, inflammatory response, calcium homeostasis alteration,

*Address correspondence to this author at Director of Institute of Neurology, Ruijin Hospital, Jiao Tong University, Shanghai, China; Tel: 86-2164370045 X 611201; Fax: 86-21-54669084; E-mail: wdle@sibs.ac.cn and mitochondrial dysfunction, all of which are responsible for neuron injury and death $[16,66,81]$. Therefore, attempt to enhance $\alpha$-secretase activity or to inhibit $\beta$-secretase and $\gamma$-secretase activity seems to be a promising strategy. Furthermore, immunotherapies using vaccine or $A \beta$ specific antibodies to degrade amyloid plaques have been shown effective in animal models of AD (Fig. 1).

\section{$\beta$-Secretase Inhibitors}

$\beta$-secretase is known as a membrane-bound aspartic acid (Asp) protease. $\beta$-secretase plays an important role in converting APP into SAPP $\beta$ and A $\beta$ production. Inhibition of $\beta$-secretase activity is expected to reduce the production of toxic amyloid plaques. $\beta$ secretase, containing leucine residue, acidic residues, and bulky hydrophobic residues, has a loose substrate specificity and its recognition site extends over several amino acids displaying poor kinetic to its known substrates [36]. Two $\beta$-secretase inhibitors named as OM99-1 and OM99-2 were shown potent inhibitory effect on the $\beta$-secretase cleavage site in APP [35, 38]. Chang et al. [19] demonstrated that $\beta$-secretase inhibitors had significant activity of $A \beta$ clearance in Tg2576 transgenic AD mice model through intraperitoneal injection of the conjugated inhibitors of $\beta$-secretase. Drugs developed from $\beta$-secretase inhibitors are expected to possess high clinical efficacy and high blood brain barrier (BBB) permeability. Arbel et al. [7] reported that intracellular and extracellular $\mathrm{A} \beta$ production can be inhibited by specific antibodies against the $\beta$-secretase cleavage site of APP. Treatment with the specific antibodies reduced the intracellular deposition of $\mathrm{A} \beta 42$ by $13 \%$ in $3 \mathrm{~h}$ accompanied by $20 \%$ reduction of membrane-bound C-terminal fragment C99 compared with control group [7]. It is believed that using specific antibodies to block the activation of $\beta$-secretase would be of interest for further investigation.

\section{$\gamma$-Secretase Inhibitors}

$\gamma$-secretase is a membrane-bound protease that cleaves within the transmembrane region of APP to generate the C-termini of the $\mathrm{A} \beta$ peptides. In addition, numerous evidences indicate that the catalytic activity of $\gamma$-secretase resides in PS1/PS2 protein which is necessary for the intercellular signaling pathway of cell-surface receptor Notch and has been linked with the production of $A \beta 42$ [5]. Dozens of missense mutations in the PS genes have been identified to be associated with early onset familial AD [7, 17, 83]. Peptidic inhibitors such as difluoroketone peptidomimetic 1 (MW167) are reported to be able to inhibit $\gamma$-secretase activity and amyloid plaques formation in $\beta$ APP transfected cell cultures [81]. Like other peptidic inhibitors, this compound can also reduce the formation of Notch intracellular domain (NICD) [81]. NICD can interact with several transcriptional factors, thus is essential for neuronal differentiation, spermatogenesis, oogenesis, and myogenesis [81]. Side effect caused by disrupted Notch receptor signaling pathway has been reported in zebrafish model [33]. Two relative new orally $\gamma$ - 


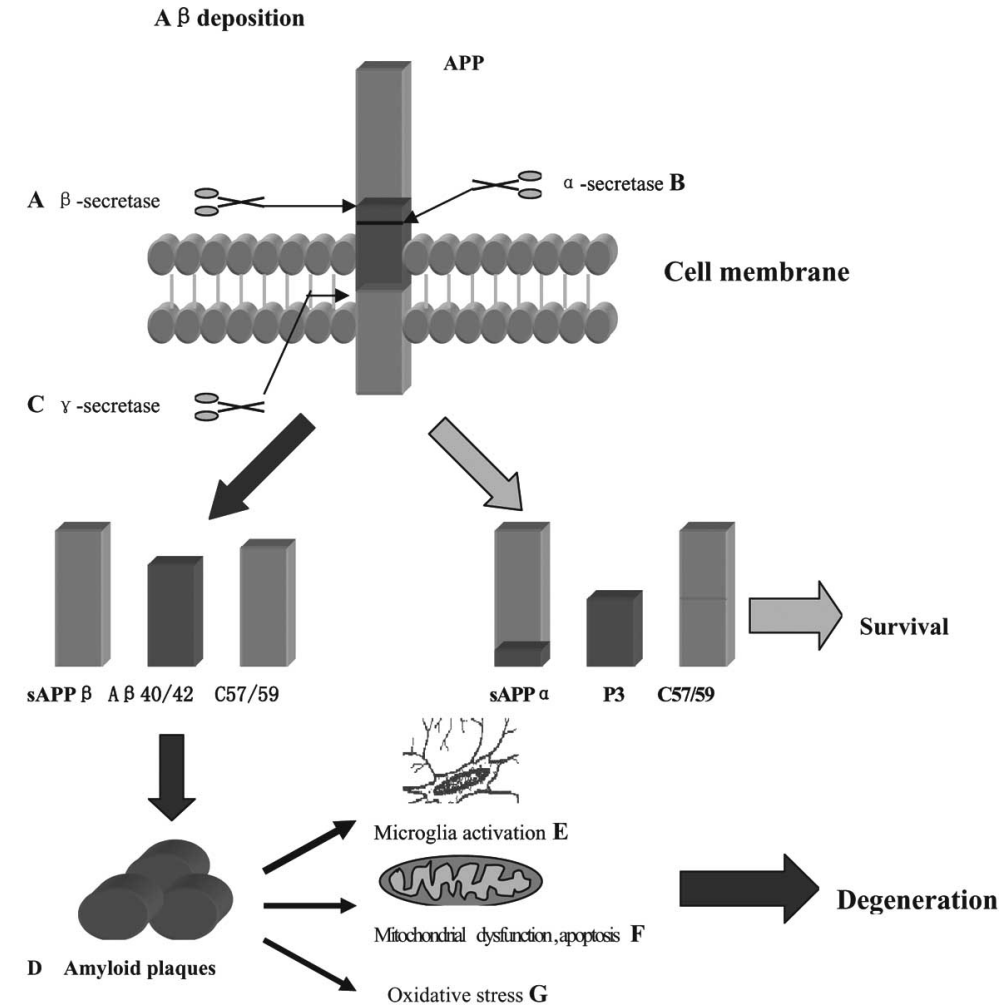

Fig. (1). Processing of amyloid precursor protein (APP) and potential therapeutic targets.

APP proteolysis undergo two different ways which include hydrolysis catalysed by $\alpha$-secretase, resulting in release of soluble $\alpha$-APPs, and the intra-membrane proteolysis catalysed by $\gamma$-secretase and produce peptides P3. The second pathway involves $\beta$-secretase catalyse which produce $\beta$-APPs and A $\beta$ peptides, which ranging in length from 40 to 42 amino acids. A $\beta 42$ peptide is prone to aggregation and formation of amyloid plaques lead to cell degeneration. Promote activation of $\alpha$-secretase (B) as well as inhibit $\beta$-secretase (A) and $\gamma$-secretase $(\mathbf{C})$ are promising targets. Immunotherapies use vaccine or A $\beta$ specific antibodies to promote amyloid plaques degradation (D) have been shown safe and effective in animal models. Anti-microglia activation (NSAID) (E) Anti-apoptotic approaches and mitochondrial dysfunciton $(\mathbf{F})$, and anti-oxidative stress agents $(\mathbf{G})$ are benefit in blocking degeneration process.

secretase inhibitors are found more effective and have fewer side effects [5, 10]. BMS 289948 (benzene sulfonamide hydrochloride) and BMS 299897, (fluorobenzenepropanoic acid) have been used in APP-YAC transgenic mice and in guinea pigs. At the dose of 100 $\mathrm{mg} / \mathrm{kg}$, the reduction effects of these compounds on brain and plasma $A \beta$ levels can be rapidly achieved within $20 \mathrm{~min}[5,10]$. In addition, these compounds exhibit little toxicity mediated by Notch inhibition [5]. Several inhibitors are currently undergoing clinical phase I trial. Another $\gamma$-secretase inhibitor, LY450139, has been reported to inhibit $A \beta$ formation in whole cell assays, in transgenic mice and in beagle dogs [74]. In clinical trial, LY450139 causes a dose-dependent $\mathrm{A} \beta$ reduction in plasma and cerebrospinal fluid. This drug is well tolerated and safe at a dose of 50mg per day [74]. Nonpeptidic inhibitors such as JLK inhibitors (JLK2, JLK6, JLK7) are highly specific and effective in blocking $\gamma$-secretase and clearing $\mathrm{A} \beta$ by approximately $80 \%$ in HEK293 cells overexpressing wild-type $\beta$-APP [62]. At a concentration of $100 \mu \mathrm{M}$ these JLK inhibitors do not interfere with Notch pathway. Furthermore, several other inhibitors such as PS1 inhibitors L-685458, L-852646, and DAPT (WO 9822494), and a novel compound NVP-AHW700NX, (a derivative of L-685458), as well as the SPP inhibitors (ZLL)2-ketone and TBL4K have been reported in preclinical studies $[5,92]$. Moreover, Nicastrin, a glycoprotein subunit of $\gamma$-secretase complex acting as a receptor to recruit relative substrates into $\gamma$ secretase, participates in conjugation to new amino terminus and generates proteolysis of extracellular APP and Notch domain [78]. Artificial compounds or antibody specifically inhibiting the binding of the $\beta$-secretase-cleaved APP to the nicastrin may have potential to become promising drugs for the treatment of $\mathrm{AD}$.

\section{$\alpha$-Secretase Activators}

The $\alpha$-secretase is a member of a disintegrin and metalloprotease (ADAM) family. Cleavage of APP by $\alpha$-secretase within the A $\beta$ peptide domain produces the neurotrophic and neuroprotective SAPP $\alpha$ that is essential for neuronal development [5]. This process can be induced by overexpression of ADAM10 family such as ADAM10 or ADAM17 (tumor necrosis factor-alpha converting enzyme) or by the activation of second messenger cascades [5]. Postina et al. [64] developed transgenic mice encoding with human mutant APP with overexpression of ADAM10 gene or catalytically inactive ADAM10 mutant gene. The secretion of the neurotrophic sAPP $\alpha$ was increased and the formation of $A \beta$ peptides was decreased with the reduction of amyloid plaques deposition in ADAM 10 overexpression models [64]. In addition, the animal models showed alleviation on cognitive deficit [64]. However, expression of mutant catalytically inactive ADAM 10 models showed an enhancement of the number and size of amyloid plaques in the brains of double-transgenic mice [64]. What is more exciting is that several agents such as muscarinic agonists, cholesterol-lowering drugs, steroid hor-mones, non-steroidal anti-inflammatory drugs can upregulate the expression of several ADAM family members through the activation of second messenger cascades [29]

Protein kinase $\mathrm{C}(\mathrm{PKC})$ is also involved in the processing of APP. A central and potentially critical locus of convergence between memory acquisition and memory loss in AD is PKC activation, which can be impaired by amyloid plaques $[28,88]$. PKC activation can induce the synthesis of proteins necessary and sufficient for subsequent long-term memory consolidation [4]. Moreo- 
ver, PKC activators benzolactam (BL) and bryostatin 1 at subnanomolar concentrations restore the function of $\mathrm{K}^{+}$channels and enhance the activation of $\alpha$-secretase significantly in fibroblast cells of AD patients [28]. These activators have been tested in APP [V717I] transgenic mice showing effectively increasing $\operatorname{sAPP} \alpha$ and reducing both $A \beta 40$ and $A \beta 42$ [28]. Treatment with bryostatin 1 attenuates the cognitive impairment and behavioral deficit in this animal model [28]. Since PKC activator plays a role in $\alpha$-secretase activation and regulates the metabolism of APP, it might be considered as a potential therapeutic agent for AD.

\section{Promotion of A $\beta$ Clearance}

$\mathrm{A} \beta$ generated from abnormal cleaves process can cause the oligomerization of the peptide and eventually lead to $A \beta$ fibrillization, plaques deposition and triggered amyloid cascade [5]. This cascade is evidently associated with inflammatory response and free radicals mediated oxidative injury [71]. In addition, the accumulation of oligomerized $\mathrm{A} \beta$ proteins is responsible for altering ionic homeostasis [5]. Excessive calcium entering into neurons can contribute to selective neuronal dysfunction and cell death. Therefore, approaches aiming at promoting $\mathrm{A} \beta$ clearance may have great potential.

There are numerous proteases in the brain that participate in $\mathrm{A} \beta$ degradation. Neprilysin, a type 2 membrane protein on the cell surface, has recently been implicated as a major extracellular A $\beta 42$ degrading enzyme in the brain. Marr et al. applied lentiviral vector that expresses human neprilysin (named Lenti-Nep) in APP [V717I] transgenic mouse [50]. Intracerebral injection of Lenti-Nep significantly reduces amyloid deposits and neuron degeneration in this mouse model [50]. Analysis of dendritic integrity with mitogenactivated protein (MAP2) antibody shows that Lenti-Nep transfection results in $16.27 \%$ more MAP2 immunoreactivity on the treated side compared with $3.7 \pm 11 \%$ decrease in control group [50]. Insulin-Degrading Enzyme (IDE), a protease helping degrade glucagons, also plays an important role in $\mathrm{A} \beta$ degradation. Recombinant IDE is reported to reduce $A \beta$ toxicity and deposition in cortical neuronal cultures $[44,56]$.

$\beta$-sheet breaker that could degrade $A \beta$ is another potential target for AD. Soto et al. [79] designed a peptide (ißA11) containing Nterminal domain of $A \beta$ that mainly contributes to $A \beta$ fibrillogenesis. This breaker can bind to $A \beta$ and block the interaction between monomers, oligomers and prevent the formation of amyloid fibrils. Soto et al. [80] reported another shorter $\beta$-sheet breaker peptide iA $\beta 5$, which inhibits amyloid formation in vitro and reduces $A \beta$ induced toxicity in human neuroblastoma cells. A new $\beta$-sheet breaker iA $\beta 5 p$ has been tested in animal models of $\mathrm{AD}[18,61]$. Double transgenic mouse model overexpressing human APP London mutation (V717I) and human PS1 A246E mutation was used. Intra-cerebroventricular injection of $2.5 \mathrm{mg}$ of $\mathrm{iA} \beta 5 \mathrm{p}$ for 8 weeks shows a $67.3 \%$ reduction of amyloid burden as compared to controls; while injection of $1 \mathrm{mg}$ iA $\beta 5 \mathrm{p}$ three times a week for 8 week reveals a $46.5 \%$ reduction of amyloid load [61]. iA $\beta 5 p$ treated mice also demonstrate an increase in neuronal survival [61]. Intra hippocampal injection of iA $\beta 5 p$ showes a reduction of the amyloid deposit and decreased astrocytic response associated with improvement in behavioral deficit after 1 month treatment [18]. iA $\beta 5 p$ is protected by acetylation in the amino terminus and amidation in the carboxyl terminus to provide high stability and BBB permeability in human plasma compared with other breakers [20, 18, 61].

Low molecular weight heparin is a traditional drug used as anticoagulation agent for the treatment of cerebral infarction and other thrombogenesis disorders. This traditional drug has come into sight because of its interfering metabolism of amyloid plaques and reducing accumulation of $\beta$-amyloid [11]. One research reported that long-term treatment with enoxaparin, a low molecular weight heparin, in APP751 transgenic mice can significantly reduce the deposition of amyloid plaques and $A \beta$ aggregation [11]. Chronic treat- ment with enoxaparin is well tolerated and does not increase side effects such as hemorrhage in the brain. Although the mechanism is not clear yet, reducing ability of $A \beta$ to activate the complement systems and its classical pathway may play a role.

Recent study also suggests that exercise may affect disease progression. It has been reported that 5 months voluntary exercise in TgCRND8 mice can lead to a decrease in extracellular A $\beta$ plaques deposition in the frontal cortex by $38 \%$ and $40 \%$ in hippocampus associated with $22 \%$ reduction in A $\beta 42$ level [2]. This effect is independent of neprilysin and IDE but related to the change in neuronal metabolism [51].

Several high lipophilicity small compounds such as Pittsburgh Compound-B (PIB) and 2-Dialkylamino-6- acylmalo-nonitrile substituted naphthalenes (FDDNP) have now been used as early biomarkers of $\mathrm{AD}[3,42]$. They are highly specific and sensitive in detecting $\mathrm{A} \beta$ deposition by $\left[{ }^{18} \mathrm{~F}\right]$ PET imaging. These compounds have been found to be able to cross the BBB and specifically bind to senile amyloid plaques and NFTs in vivo in the human brain [3, 42]. Furthermore, the discovery of a new binding site of FDDNP and PIB to amyloid plaques also helps in the optimization of the A $\beta$ degradation potency of experimental drugs and opens a new avenue for the early treatment of $\mathrm{AD}$ [68].

\section{IMMUNOTHERAPY FOR THE TREATMENT OF AD}

Immunotherapy has been demonstrated effectively in removal of proteins which accumulate abnormally in animal models of AD and other dementias [14]. Several immunotherapies for AD have been tried in mouse models with transgenic Swedish mutant APP gene [94]. These models develop diffuse deposits of amyloid plaques in the brain at the middle age. Schenk and his colleagues [73] reported that once the transgenic mice were injected with human A $1-42$ (AN-1792) these mice produce high titer antibodies against the peptide. Bard et al. [9] reported that antibodies administrated systematically could enter the CNS and bind to $A \beta$, followed by recruitment and activation of microglia, indicating that microglia-triggered phagocytose may play a role in the clearance of amyloid plaques. Other research suggested that long-term systematical administration of specific monoclonal $(\mathrm{m} 266)$ antibodies disrupts the $\mathrm{A} \beta$ equilibrium between the CNS and plasma and leads to an increasing of $A \beta$ efflux out of the brain into the periphery where it is degraded [23]. Resent studies demonstrated that antibodies could direct against $\mathrm{A} \beta 42$ and inhibit both fibrillogenesis and cytotoxicity [32]. Weiner et al. [93] used oral or nasally administered A $\beta 40$ to immunize the PDAPP mice and find a $60 \%$ reduction in amyloid burden. In another mice model (Tg2576), immunization with a nontoxic and nonfibrillar $\beta$ amyloid homologous peptide has been shown to reduce AD associated pathology [76]. Nonfibrillogenic $\mathrm{A} \beta$ derivative K6A beta1-30 has been reported equally benefit for amyloid burden reduction and cognitive improvement with fewer side effects in the mouse model [75]. Furthermore, the reduction of $A \beta$ level linked to behavioral improvement is observed in TgCRND8 model [52]. Clinical trials using A 342 (AN-1792) started in 2001 after preclinical tests in several species of animal models. The clinical trial results seem promising after phase I trials but stopped 1 years later in clinical phaseII because of 18 of $298(6 \%)$ patients treated with AN1792 eventually suffered from encephalitis compared with 0 of 74 on placebo [59]. Neurophathological examination of the brain in the patients reveals CD4+ T and CD8+ T cells infiltration in neocortex and macrophages infiltration in white matter [58]. For most patients, A $\beta 42$ immunization provides effective immune response and promotes amyloid plaques degradation. In addition, Hock et al. [37] demonstrated that patients who receive active immunization show slower rate decline in cognitive function and the treatment is well tolerated. Immunization with the fulllength $A \beta 42$ peptide, containing both $B$ and $T$ cell epitopes, can be more effective in enhancing $T$ cell activation to $A \beta$ clearance [32]. It is desired to have Th2 immune response to promote antibody 
production and inhibit proinflammatory Th1 response that could activate imbroglio-induced cytokine release and neurotoxicity [32]. DNA vaccination may open up a new avenue for treatment of $A D$. Ghochikyan et al. [34] constructed a DNA minigene with A $\beta 42$ fused to mouse interleukin-4 as a molecular adjuvant to generate anti-A $\beta$ antibodies. This compound successfully enhances the Th2 immune responses and induces the generation of IgG1 and IgG2b $\mathrm{A} \beta$ antibodies recognize plaques [34]. Qu et al. [67] vaccinated mice with plasmid encoding $A \beta 42$. The mice elicit humoral immune responses against $A \beta$ peptides without Th1-cell-mediated cytotoxic $\mathrm{T}$ lymphocyte response, suggesting that gene vaccination is relatively safe [67]. Nasal vaccination with a proteosome-based adjuvant (IVX-908) plus glatiramer acetate (GA), a synthetic copolymer used to treat multiple sclerosis is effective in reducing $\mathrm{A} \beta$ plaques deposition in an AD mouse model [31]. GA plus IVX-908 treated group shows $84 \%$ reduction in $\mathrm{A} \beta$ accumulation compared with $50 \%$ reduction in the $\mathrm{A} \beta$ vaccination group in APP-Tg mice [31]. Such treatment does not require the presence of antibody but the microglia-mediated $\mathrm{A} \beta$ clearance.

Passive immunotherapy includes administration of specific $\beta$ amyloid peptide antibodies that would bypass immune response and would not lead to $\mathrm{T}$ cell-mediated encephalitis. $\beta$-amyloid peptide antibodies (10D5) not only inhibit aggregation of $A \beta$ but also reduce plaque-induced neuritic alterations and cytotoxicity in APP [V717I] transgenic mouse model [48]. Clinical study indicates that intravenous administration of immunoglobulin (IVIg) containing $\beta$ amyloid peptide antibodies to 6 elderly patients with sporadic AD show significant cognitive improvement after the 6 months of therapy [25]. Although no meningoencephalitis case is reported so far, cerebral hemorrhage has been observed in mouse model [63]. In addition, to maintain stable levels of antibodies in serum requires repeated administration [63].

\section{AGENTS INHIBIT NEUROFIBRILLARY TANGLES (NFTS) IN AD}

Another pathologically hallmark of AD is NFTs, which are composed of intracellular filamentous aggregates of hyperphosphorylated microtubule (MT)-associated tau protein, self-conversion into paired helical filaments (PHF-tau). Numerous mutations of tau gene have been detected in chromosome 17 that is linked to several forms of frontotemporal dementias [21]. Dysfunction of tau proteins is responsible for the failure of the self-assembling tau to regulate the MT dynamics that is essential for cell survival. Drugs targeting tau hyperphosphorylation and NFTs may benefit for slowing $\mathrm{AD}$ progression (Fig. 2). Formation of NFTs and PHF-tau in AD is not due to mutations in the tau gene but rather to some cellular cascade including $A \beta$ activation that leads to abnormal hyperphosphorylation of tau proteins [54]. Tau can be phosphorylated by several kinases including glycogen synthase kinase-3 $\beta$ (GSK3 $\beta$ ) and cyclin-dependent kinase 5 (CDK5) that can be regulated by A $\beta$ deposition [47]. Inhibition of cellular GSK3 $\beta$ by lithium or GSK $\beta$ antisense reduced $A \beta$ aggregation [47]. However, Ryder et al. [72] reported that inhibition of CDK5 activity by CDK5 inhibitor roscovitine or CDK5 antisense could enhance $A \beta$ production. In addition, CDK5 activity can be regulated by a $25-\mathrm{kDa}$ protein $\mathrm{P} 25$, which is generated from a myristoylated membrane-attached protein P35 to undergo calpain-mediated cleavage. The CDK5/P25 complex could be delocalized from the plasma membrane and may result in phosphorylation of substrates such as tau [54]. Based on structural insight into diversity ATP-binding site of different kinases through crystallizing technology, specific and selective kina-ses inhibitors become more achievable [54]. AR-A014418 is a specific and selective GSK3 $\beta$ inhibitor without interfering with CDK5 and CDK2 pathway [12]. This compound inhibits tau phosphorylation at a GSK3-specific site (Ser-396) in an ATP-competitive manner in cells and provides neuroprotection by block GSK3 $\beta$ mediated pathway activated by $\mathrm{A} \beta$ [12]. In addition, AR-A014418

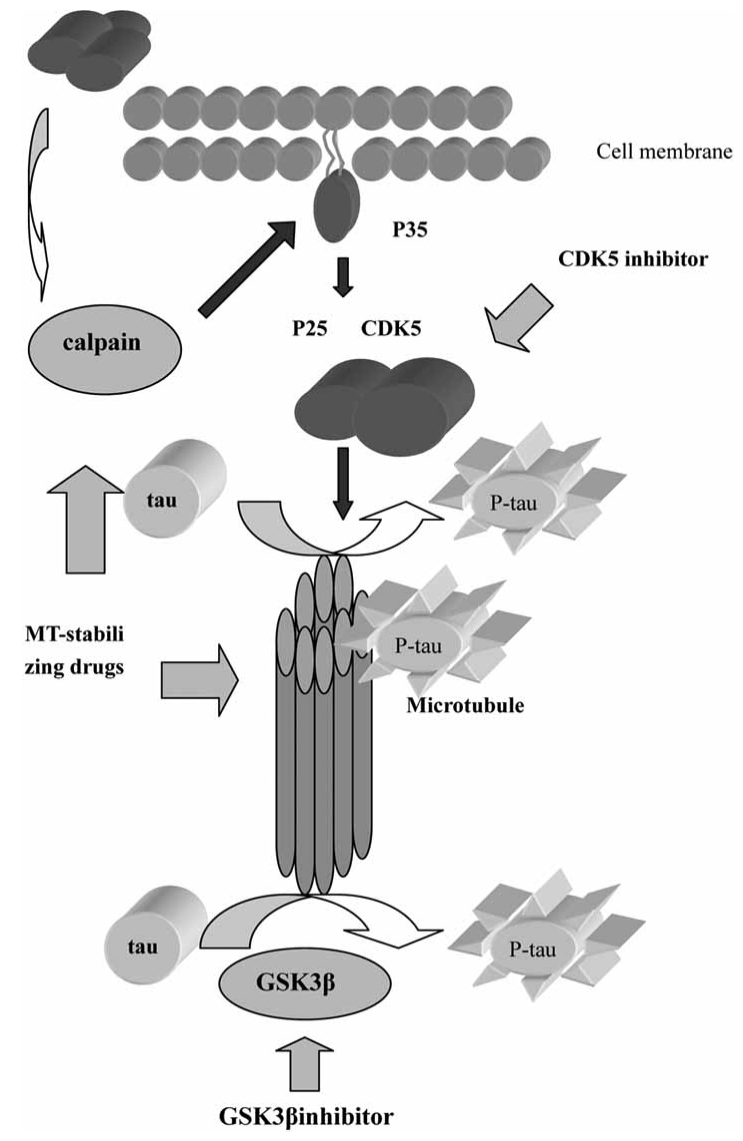

Fig (2). Tau phosphorylation procedures and related target site. Deposition of extracellular A $\beta$ may lead to activation of GSK $3 \beta$ pathway and calpain-mediated pathway includes generation of P25 from P35 that results in formation of P25 and CDK5 complex. However, the complex plays an important role in transforming tau to hyperphosphorylated tau. Develop specific GSK3 $\beta$ inhibitor, CD5K inhibitor and MT-stabilizing drugs may attenuate the formation of hyperphosphorylated tau that would benefit for AD.

protected N2A neuroblastoma cells against cell death mediated by inhibition of the phosphatidylinositol 3-kinase and protein kinase $\mathrm{B}$ survival pathway [12]. MT-stabilizing drugs have now been caught a lot of attention because these agents could enhance neuron survival and reduce $A \beta$-induced apoptosis [54]. MT-stabi-lizing agents such as paclitaxel that not only enhance neuron survival by blocking $\mathrm{A} \beta$-mediated cytotoxicity but also inhibit both CDK5-induced phosphorylation and calpain-mediated cleavage of P35 to P25 [45, 53]. Paclitaxel does not directly inhibit CDK5 rather blocks $A \beta$ induced calpain activation and decrease the formation of CDK5 activator P25 $[45,53]$. Resent research highlights the androgens in preventing tau hyperphosphorylation [60]. Papasozomenos et al. [60] showed that testosterone provides protection through inhibiting heat shock protein mediated activation of GSK3 $\beta$ in rat models [60]. This result suggests that hormone replacement therapy might be useful in AD prevention.

\section{SMALL INTERFERING RNA FOR THE TREATMENT OF AD}

Approaches targeting mRNA recognition and its down-regulation of specific genes are based on the antisense action of small inhibitory nucleic acids such as small interfering RNA (siRNA). siRNA recognizes the target molecule via sequence- specific Watson-Crick base- pairing then leading to the formation of a complementary siRNA/mRNA duplex that initiates inhibition of translation of target mRNA. Design specific siRNA targeting to $\beta$-secretase and $\gamma$-secretase that affects leavage of APP may be a potential 
therapeutic approach for the treatment of AD [57]. Luo et al. [49] used three siRNAs that recognize specific sequence of PS1 in Chinese hamster ovary (CHO) cell line transfected with mutant PS1 gene and $\beta A P P$ gene of AD patients (CHO/PS1/ APP). The expression of PS1 and generation of A 342 is significantly reduced after siRNA interference in a time-depen-dent and dose-dependent manner [49]. Miller et al. [55] constructed siRNAs that are specific against a tau mutation (V337M) and APP mutation (APPsw). These allele-specific siRNAs successfully silence the mutant tau and APP expression [55]. Silence the expression of $\beta$-secretase by siRNA is found effectively blocking the formation of amyloid plaques [77]. Lentiviral vectors expressing siRNAs targeting $\beta$-secretasel can reduce amyloid production and improve behavioral deficits in APP transgenic mice [77]. Furthermore, $\beta$-secretase silence also provides neuroprotection by reducing formation of free radical, oxidative stress and neurotoxicity [41]. It is believed that selectively silencing mutant genes which cause AD represents a novel therapeutic alternative for the treatment of $\mathrm{AD}$ and related dementias.

Other approaches designed to inhibit $\beta$-secretase gene expression include applications of antisense oligonucleotides. A 25-nt antisense oligomers directly against aspartyl protease mRNA have been documented to significantly reduce the $\beta$-secretase transcription level and the $A \beta 40$ and $A \beta 42$ peptides levels by $50-80 \%$ in HEK293 cells overexpressing APP695 with Swedish mutation [57]. Antisense, ribozyme and deoxyribozyme strategies have been the subjects of many pre-clinical trials in recent years [43].

\section{GENE AND CELL THERAPY IN AD}

Since nerve growth factor (NGF) was discovered to rescue cholinergic neurons from apoptosis in 1986, gene therapy with NGF, glial derived neurotrophic factor (GDNF), brain derived neurotrophic factor (BDNF) and neprilysin for the treatment of $A D$ and related neurodegenerative disorders has been undergoing various experimental and clinical trials [8, 87]. These therapies have been reported not only effective in preventing degeneration of cholinergic neurons but also in ameliorating behavioral deficit and memory impairment in animal models of AD [15]. However, it is a challenge to establish a delivery system that is safe, high efficacy and simple [74]. Dodart and colleagues [24] directly deliver lentiviral vectors expressing three common human apoE isoforms (apoE2, apoE3, and apoE4) into mouse cerebrum. Gene delivery of apoE2 shows reduction of $A \beta$ burden and formation of amyloid plaques while apoE4 gene livery displays a contrary result [24]. NGF is another target of gene therapy for AD [85]. A phase I clinical trial of NGF gene for $\mathrm{AD}$ has been initiated in USA. Patients received NGF secreting autologous fibroblasts that are implanted in the region of Meynert nucleus are well tolerated and their cognitive decline is improved in correlation with an increasing in metabolic activity in the cortex detected by PET scan $[15,86]$.

Stem cells are another potential resource of therapy for the treatment of AD because of its ability to differentiate into all kinds of neuronal cells. Transplantation of cholinergic neuronal stem cells has been reported to result in memory improvement and elevation in numbers of cholinergic neurons in vitro and in vivo [91]. In animal models of $\mathrm{AD}$, stem cell transplantation has showed some promising results in preventing disease progression [39, 82]. With the advances in gene switch technology, the stem cells become more controllable in regulating target gene expression and promoting the differentiation of stem cells into designed neurons.

\section{MULTIFUNCTIONAL NEUROPROTECTIVE AND NEU- RORESCUE DRUGS FOR AD}

Resent therapeutic designs are interested in multi-targets drugs which may provide different and diverse neuroprotective effects aimed at increasing the expression of $\operatorname{sAPP} \alpha$, decreasing the levels of $\mathrm{A} \beta$, protecting mitochondrial function and providing antiapoptosis $[95,96]$. These agents with various CNS targets are poten- tial to become therapeutic drugs for the treatment of AD and other neurodegenerative disorders. Several of these drugs are undergoing clinical trials [89], including ladostigil (TV3326) [(N-propargyl(3R) aminoindan-5yl)-ethyl methyl carbamate], which combine rasagiline, a selective monoamine oxidase (MAO)-B inhibitor, with cholinesterase $(\mathrm{ChE})$ inhibiter rivastigmine or iron chelator M30 [96]. It has been reported that ladostigil is effective in stimulating the expression of anti-apoptotic genes Bcl-2 and pPKC, and inhibiting apoptotic-induced genes Bax, Bad and caspase 3. In addition, ladostigil can enhance $\mathrm{sAPP} \alpha$ via protein kinase C-MAP kinase dependent pathway and decrease the levels of holo-APP [95, 96] (Fig. 3). In clinical trial, ladostigil has been shown in improving cognitive function and memory impairment induced by scopolamine in rat model through its ChE inhibitory activity $[89,95,96]$. The development of multifunctional drugs aimed at multiple therapeutic targets to both pathology and mechanism of disease may achieve a great degree of success by improving clinical manifestation and delaying disease progression in molecular and biological levels.

\section{ANTI-OXIDATIVE, ANTI-INFLAMMATORY AND ANTI- APOPTOTIC AGENTS FOR AD}

Accumulating evidences indicate that oxidative stress, microglia-mediated inflammatory response and caspase-mediated apoptosis increase neuron damage and exacerbate AD pathogenesis $[6,26$, 40]. The expression of apoptotic genes caspase 3 , caspase 8 and caspase 9 has been reported elevated in the brains of patients with $\mathrm{AD}$ [5]. Whether this process is triggered by $\mathrm{A} \beta$ deposition still remains a further investigation. Troy et al. [84] reported that A $\beta$ cytotoxicity is related to c-Jun NH2-terminal kinase (JNK) and caspases, both of which can be potential target sites for drug development. Several anti-oxidative agents or free radical scavengers such as Vitamin E and Idebenone have been shown valuable in attenuating disease progression by reducing $A \beta$-induced oxidative damage in clinical trials [5]. Because of well tolerance and relative safe, these anti-oxidants and radical scavengers are believed useful in $\mathrm{AD}$ prevention. Long-term use of non-steroidal anti-inflammatory drugs (NSAIDs) is found to reduce risk for the development of $\mathrm{AD}$ [27]. NSAIDs are effective in blocking microglia activation and lowering the levels of $A \beta 42$ through interfering $\gamma$-secretase function [27]. In addition, NSAIDs such as aspirin have been reported not only inhibiting iNOS production by interfering its synthesis and catalysis but also providing neuroproteciton by abolishing $\mathrm{NO}_{2}-$ $+\mathrm{NO}_{3}$ - accumulation in cell-free media [5]. Other experimental therapies for the treatment of AD include metal chelators and excitatory toxic amino acid (EAA) blockers as summarized in (Table 1).

Epigallocatechin gallate (EGCG), a major monomer of green tea polyphenol, has been demonstrated to block microglia-induced neuronal damage through inhibition of NO and TNF- $\alpha$ secretion from activated microglia [46]. A recent study reported that EGCG can reduce amyloid plaques deposition and promote $\alpha$-secretase proteolytic pathway, which may suggest that EGCG dietary supplementation may be a prophylaxis therapeutic choice for $\mathrm{AD}$ [69].

\section{ADENOSINE RECEPTOR ANTAGONIST}

Currently, the greatest interest of adenosine A2A receptor antagonist is associated with its neuroprotective effect against neurodegenerative disorders such as $\mathrm{AD}$ and Parkinson's disease (PD). Selective A2A receptor antagonist can inhibit the neuronal degeneration caused by exposure of rat cultured cerebellar granule neurons to fragment $25-35$ of A- $\beta$, suggesting this agent may be effective in anti-neuronal toxicity and oxidative stress [22].

\section{CONCLUSION AND OUTLOOK}

The advances in understanding molecular and genetic mechanisms of AD lead to discovery of various potential therapeutic tar- 


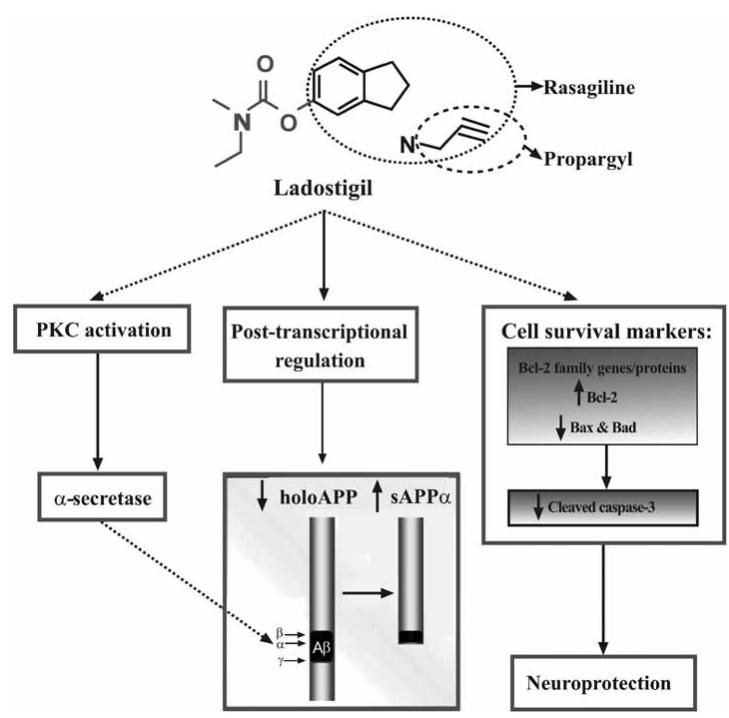

Fig (3). Proposed schematic model for the dual effects of ladostigil: neuroprotection and regulation/processing of holo-APP [Replicated from Yogev-Falach, M., et al., (2006) FASEB].

gets and provide us hope that new drugs acting on these targets could delay disease progression. Several of these therapies are now under clinical investigation and evaluation. Immunotherapy, which shows optimism in reducing $\mathrm{AD}$ pathology in transgenic mice, confronts small but significant problems resulted from abnormal TH1 cell activation in clinical trials. However, vaccination with genes encoding specific sequences may enlighten the future of immunotherapy. Sequence-specific downregulation of $\beta$-secre-tase 1 by small inhibitory nucleic acids including siRNA and antisense oligonucleotides has successfully lowered $A \beta$ formation in experimental trials. Although neuronal stem cell transplantation and gene intervention are still in preclinical testing, the preliminary data suggest that these therapies may have some benefits. Multifunctional agents such as rasagiline and ladostigil as well as EGCG have been demonstrated to possess both anti-amyloid deposition and antiapoptotic effects, which can be used as preventive therapy for AD. With the new knowledge and findings of the causes and pathogenesis of $\mathrm{AD}$, we believe that many more therapeutic targets will be identified, through which new drugs will be discovered and tested, and the ultimate goals to prevent or reverse the neurodegeneration in $\mathrm{AD}$ are sure to be achieved.

\section{ACKNOWLEDGMENT}

This work was supported by National Science Foundation of China (No. 30370491), a research grant (E03003) from High Education Commission of Shanghai, Municipality and Research Fund (03DZ14021) from Science and Technology Commission of Shanghai Municipality. We also appreciated Professor Youdim MB (Technion-Rappaport Family Faculty of Medicine, Eve Topf and NPF Centers for Neurodegenerative Diseases, Department of Pharmacology, Haifa, Israel.) for his critical reading and providing materials for this review paper.

\section{REFERENCES}

[1] Adessi, C., Frossard, M.J., Boissard, C., Fraga, S., Bieler, S., Ruckle, T., Vilbois, F., Robinson, S.M., Mutter, M., Banks, W.A., Soto, C. (2003) Pharmacological profiles of peptide drug candidates for the treatment of Alzheimer's disease. $J$. Biol. Chem., 278, 13905-11.

[2] Adlard, P.A., Perreau, V.M., Pop, V., Cotman, C.W. (2005) Voluntary exercise decreases amyloid load in a transgenic model of Alzheimer's disease. J. Neurosci., 25, 4217-21.

[3] Agdeppa, E.D., Kepe, V., Liu, J. (2003) 2-Dialkylamino-6- acylmalononitrile substituted naphthalenes (DDNP analogs): novel diagnostic and therapeutic tools in Alzheimer's disease. Mol. Imaging Biol., 5, 404-17.

[4] Alkon, D.L., Epstein, H., Kuzirian, A., Bennett, M.C, Nelson, T.J. (2005) Protein synthesis required for long-term memory is induced by PKC activa- tion on days before associative learning. Proc. Natl. Acad. Sci. USA, 102, 16432-7.

[5] Anderson, J.J., Holtz, G., Baskin, P.P. (2005) Reductions in beta-amyloid concentrations in vivo by the gamma-secretase inhibitors BMS-289948 and BMS-299897. Biochem. Pharmacol., 69, 689-98.

[6] Appel, S.H., Smith, R.G., Le, W.D. (1996) Immune-mediated cell death in neurodegenerative disease. Adv. Neurol., 69, 153-9.

[7] Arbel, M., Yacoby, I., Solomon, B. (2005) Inhibition of amyloid precursor protein processing by $\beta$-secretase through site-directed antibodies. Proc. Natl. Acad. Sci. USA, 102, 7718-23.

[8] Arenas, E. (1996) GDNF, a multispecific neurotrophic factor with potential therapeutic applications in neurodegenerative disorders. Mol. Psychiatry, 1, 179-82

[9] Bard, F., Cannon, C., Barbour, R., Burke, R.L., Games, D., Grajeda, H. Guido, T., Hu, K., Huang, J., Johnson-Wood, K. (2000) Peripherally administered antibodies against amyloid beta-peptide enter the central nervous system and reduce pathology in a mouse model of Alzheimer disease. Nat. Med., 6, 916-919.

[10] Barten, D.M., Guss, V.L., Corsal, J.A., Loo, A., Hansel, S.B., Zheng, M (2005) Dynamics of \{beta $\}$-amyloid reductions in brain, cerebrospinal fluid, and plasma of $\{$ beta $\}$-amyloid precursor protein transgenic mice treated with a \{gamma\}-secretase inhibitor. Pharmacol. Exp. Ther, 312, 635-43.

[11] Bergamaschini, L., Rossi, E., Storini, C., Pizzimenti, S., Distaso, M., Perego, C. (2004) Peripheral treatment with enoxaparin, a low molecular weight heparin, reduces plaques and beta-amyloid accumulation in a mouse model of Alzheimer's disease. J. Neurosci., 24, 4181- 4186.

[12] Bhat, R., Xue, Y., Berg, S., Hellberg, S., Ormo, M., Nilsson, Y., Radesater, A.C., Jerning, E. (2003) Structural insights and biological effects of glycogen synthase kinase 3-specific inhibitor AR-A014418. J. Biol. Chem., 278, 45937-45

[13] Blesch, A., Tuszynski, M.H. (2004) Gene therapy and cell transplantation for Alzheimer's disease and spinal cord injury. Yonsei. Med. J., 45, 28-31.

[14] Boche, D., Nicoll, J.A., Weller, R.O. (2005) Immunotherapy for Alzheimer's disease and other dementias. Curr. Opin. Neurol., 18, 720-5.

[15] Braddock, M. (2005) Safely slowing down the decline in Alzheimer's disease: gene therapy shows potential. Expert Opin. Investig. Drugs, 14, 913-5.

[16] Bubber, P., Haroutunian, V., Fisch, G., Blass, J.P., Gibson, G.E. (2005) Mitochondrial abnormalities in Alzheimer brain: mechanistic implications. Ann. Neurol., 57, 695-703.

[17] Cataldo, A.M., Peterhoff, C.M., Schmidt, S.D., Terio, N.B., Duff, K., Beard, M., Mathews, P.M., Nixon, R.A. (2004) Presenilin mutations in familial Alzheimer disease and transgenic mouse models accelerate neuronal lysosomal pathology. J. Neuropathol. Exp. Neurol., 63, 821-30.

[18] Chacon, M.A., Barria, M.I., Soto, C., Inestrosa, N.C. (2004) Beta-sheet breaker peptide prevents Abeta-induced spatial memory impairments with partial reduction of amyloid deposits. Mol. Psychiatry, 9, 953-61.

[19] Chang, W.P., Koelsch, G., Wong, S., Downs, D., Da, H., Weerasena, V., Gordon, B., Devasamudram, T., Bilcer, G., Ghosh, A.K., Tang, J. (2004) In vivo inhibition of Abeta production by memapsin 2 (beta-secretase) inhibitors. J. Neurochem., 89, 1409-16.

[20] Clark, C.M., Karlawish, J.H. (2003) Alzheimer disease: Current concepts and emerging diagnostic and therapeutic strategies. Ann. Intern. Med., 138, 400410.

[21] Cruts, M., Rademakers, R., Gijselinck, I., van der Zee, J., Dermaut, B., de Pooter, T., de Rijk, P., Del-Favero, J., van Broeckhoven, C. (2005) Genomic 
architecture of human $17 \mathrm{q} 21$ linked to frontotemporal dementia uncovers a highly homologous family of low-copy repeats in the tau region. Hum. Mol. Genet. 14, 1753-62.

[22] Dall'Igna, O.P., Porciuncula, L.O., Souza, D.O., Cunha, R.A., Lara, D.R. (2003) Neuroprotection by caffeine and adenosine A2A receptor blockade of beta-amyloid neurotoxicity. Br. J. Pharmacol., 138, 1207-9.

[23] DeMattos, R.B., Bales, K.R., Cummins, D.J., Dodart, J.C., Paul, S.M., Holtzman, D.M. (2000) Peripheral anti-A beta antibody alters CNS and plasma A beta clearance and decreases brain A beta burden in a mouse model of Alzheimer's disease. Proc. Natl. Acad. Sci. USA, 98, 8850-8855.

[24] Dodart, J.C., Marr, R.A., Koistinaho, M., Gregersen, B.M., Malkani, S., Verma, I.M., Paul, S.M. (2005) Gene delivery of human apolipoprotein E alters brain Aßburden in a mouse model of Alzheimer's disease. Proc. Natl. Acad Sci. USA, 102, 1211-1216.

[25] Dodel, R.C., Du, Y., Depboylu, C., Hampel, H., Froich, L., Haag, A., Hemmeter, U., Paulsen, S., Teipel, S.J., Brettschneider, S., Moler, H.J., Wei, X., Farlow, M., Sommer, N., Oertel, W.H. (2004) Intravenous immunoglobulins containing antibodies against b-amyloid for the treatment of Alzheimer's disease. J. Neurol. Neurosurg. Psychiatry, 75, 1472-4.

[26] Engelhardt, J.I., Le, W.D., Siklos, L., Obal, I., Boda, K., Appel, S.H. (2000) Stereotaxic injection of IgG from patients with Alzheimer disease initiates injury of cholinergic neurons of the basal forebrain. Arch. Neurol., 57, 681-6.

[27] Eriksen, J.L., Sagi, S.A., Smith, T.E., Weggen, S., Das, P. (2003) NSAIDs and enantiomers of flurbiprofen target $\gamma$-secretase and lower $\mathrm{A} \beta 42$ in vivo. $J$. Clin. Invest., 112, 440-449.

[28] Etcheberrigaray, R., Tan, M., Dewachter, I., Kuiperi, C. (2004)Therapeutic effects of PKC activators in Alzheimer's disease transgenic mice. Proc. Natl. Acad. Sci. USA, 101, 11141-11146.

[29] Fahrenholz, F., Postina, R. (2006) $\alpha$-secretase activation- An approach to Alzheimer's disease therapy. Neurodegener. Dis., 3, 255-261.

[30] Feldman, H., Gauthier, S., Hecker, J., Vellas, B., Subbiah, P., Whalen, E., the Donepezil MSAD Study Investigators Group. (2001) A 24-week, randomized, double-blind study of donepezil in moderate to severe Alzheimer's disease. Neurology, 57, 613-20.

[31] Frenkel, D., Maron, R., Burt, D.S., Weiner, H.L. (2005) Nasal vaccination with a proteosome-based adjuvant and glatiramer acetate clears beta-amyloid in a mouse model of Alzheimer disease. J. Clin. Invest., 115, 2423-2433.

[32] Gelinas, D.S., Salilva, K., Fenili, D., George-Hyslop, P., Mclaurin, J. (2004) Immunotherapy for Alzheimer's disease. Proc. Natl. Acad. Sci. USA, 101, $14657-14662$

[33] Geling, A., Steiner, H., Willem, M., Bally-Cuif, L., Haass, C. (2002) A gamma-secretase inhibitor blocks Notch signaling in vivo and causes a severe neurogenic phenotype in zebrafish. EMBO Rep., 3, 688-94

[34] Ghochikyan, A., Vasilevko, V., Petrushina, I., Movsesyan, N., Babikyan, D. (2003) Generation and characterization of the humoral immune response to DNA immunization with a chimeric beta-amyloid-interleukin-4 minigene. Eur. J. Immunol., 33, 3232-41.

[35] Ghosh, A.K., Shin, D., Downs, D., Koelsch, G., Lin, X., Ermolieff, J., Tang, J. (2001) Design of potent inhibitors for human brain Memapsin 2 ( $\beta$ secretase). J. Am. Chem. Soc., 122, 3522-3523.

[36] Gruninger-Leitch, F., Schlatter, D., Kung, E., Nelbock, P., Dobeli, H. (2002) Substrate and inhibitor profile of $\beta$-secretase (beta-secretase) and comparison with other mammalian aspartic proteases. J. Biol. Chem., 277, 4687-93.

[37] Hock, C., Konietzko, U., Streffer, J.R., Tracy, J., Signorell, A. (2003) Antibodies against beta-amyloid slow cognitive decline in Alzheimer's disease. Neuron, 38, 547-54.

[38] Hong, L., Koelsch, G., Lin, X., Wu, S., Terzyan, S., Ghosh, A.K., Zhang, X.C., Tang, J. (2000) Structure of the protease domain of memapsin 2 ( $\beta$ secretase) complexed with inhibitor. Science (Wash DC), 290, 150-153

[39] Hughes, I.A. (2004) A perspective on stem cells by a clinician. Eur. J. Endocrinol., 151(Suppl. 3), U3-5.

[40] Kalman, J., Engelhardt, J.I., Le, W.D., Xie, W., Kovacs, I., Kasa, P., Appel, S.H. (1997) Experimental immune-mediated damage of septal cholinergic neurons. J. Neuroimmunol., 77, 63-74.

[41] Kao, S.C., Krichevsky, A.M., Kosik, K.S., Tsai, L.H. (2004) $\beta$-secretase1 suppression by RNA interference in primary cortical neurons. J. Biol. Chem., 279, 1942-1949.

[42] Klunk, W.E., Engler, H., Nordberg, A., Wang, Y., Blomqvist, G., Holt, D.P. (2004) Imaging brain amyloid in Alzheimer's disease with Pittsburgh Compound-B. Ann. Neurol., 55, 306-19.

[43] Kurreck, J. (2003) Antisense technologies, improvement through novel chemical modifications. Eur. J. Biochem., 270, 1628-44.

[44] Leissring, M.A., Farris, W., Chang, A.Y., Walsh, D.M., Wu, X., Sun, X., Frosch, M.P., Selkoe, D.J. (2003) Enhanced proteolysis of beta-amyloid in APP transgenic mice prevents plaque formation, secondary pathology, and premature death. Neuron, 40, 1087-93.

[45] Li, G., Faibushevich, A., Turunen, B.J., Yoon, S.O., Georg, G., Michaelis, M.L., Dobrowsky, R.T. (2003) Stabilization of the cyclin-dependent kinase 5 activator, p35, by paclitaxel decreases beta-amyloid toxicity in cortical neurons. J. Neurochem., 84, 347-62.

[46] Li, R., Huang, Y.G., Du, F., Le, W.D. (2004) (-)-Epigallocatechin gallate inhibits lipopolysaccharide-induced microglial activation and protects against inflammation-mediated dopaminergic neuronal injury. J. Neurosci. Res., 78, 723-31
[47] Li, X., Lu, F., Tian, Q., Yang, Y., Wang, Q., Wang, J.Z. (2005) Activation of glycogen synthase kinase-3 induces Alzheimer-like tau hyperphosphorylation in rat hippocampus slices in culture. J. Neural Transm., 113(1), 93-102.

[48] Lombardo, J.A., Stern, E.A., Mclellan, M.E., Kajdasz, S.T., Hickey, G.A., Bacskai, B.J., Hyman, B.T. (2003) $\beta$ Amyloid-antibody treatment leads to rapid normalization of plaque-induced neuritic alterations. J. Neurosci., 23, $10879-10883$

[49] Luo, H.M., Deng, H., Xiao, F., Gao, Q., Weng, W., Zhang, P.F., Li, X.G. (2004) Down-regulation amyloid $\beta$-protein 42 production by interfering with transcript of presenilin 1 gene with siRNA. Acta Pharmacol. Sin., 25, 16131618.

[50] Marr, R.A., Rockenstein, E., Mukherjee, A., Kindy, M.S. (2003) Neprilysin gene transfer reduces human amyloid pathology in transgenic mice. J. Neurosci., 23, 1992-1996.

[51] Marx, J. (2005) Alzheimer's disease. Play and exercise protect mouse brain from amyloid buildup. Science, 307, 1547.

[52] McLaurin, J, Cecal, R., Kierstead, M.E, Tian, X, Phinney, A.L., Manea, M., French, J.E., Lambermon, M.H., Darabie, A.A., Brown, M.E., Janus, C., Chishti, M.A., Horne, P., Westaway, D., Fraser, P.E., Mount, H.T., Przybylski, M., St George-Hyslop, P. (2002) Therapeutically effective antibodies against amyloid-beta peptide target amyloid-beta residues 4-10 and inhibit cytotoxicity and fibrillogenesis. Nat. Med., 8, 1263-9.

[53] Michaelis, M.L., Chen, Y., Hill, S., Reiff, E., Georg, G., Rice, A., Audus, K. (2002) Amyloid peptide toxicity and microtubule-stabilizing drugs. J. Mol. Neurosci., 19, 101-5.

[54] Michaelis, M.L. (2003) Drugs targeting Alzheimer's disease: some things old and some things new. J. Pharmacol. Exp. Ther., 304, 897-904.

[55] Miller,V.M., Gouvion, C.M., Davidson, B.L., Paulson, H.L. (2004) Targeting Alzheimer's disease genes with RNA interference: an effcient strategy for silencing mutant alleles. Nucleic Acids Res., 2, 661-668.

[56] Mukherjee, A., Song, E., Kihiko-Ehmann, M., Pyrek, J.S., Estus, S., Hersh, L.B. (2000) Insulysin hydrolyzes amyloid beta peptides to products that are neither neurotoxic nor deposit on amyloid plaques. J. Neurosci., 20, 87458749.

[57] Nawrot, B. (2004) Targeting $\beta$-secretase with small inhibitory nucleic acids a future for Alzheimer's disease therapy. Acta Biochim. Pol., 51, 431-444.

[58] Nicoll, J.A., Wilkinson, D., Holmes, C., Steart, P., Markham, H., Weller, R.O. (2003) Neuropathology of human Alzheimer disease after immunization with amyloid-beta peptide: a case report. Nat. Med., 9, 448-52.

[59] Orgogozo, J.M., Gilman, S., Dartigues, J.F., Laurent, B., Puel, M., Kirby, L.C., Jouanny, P., Dubois, B., Eisner, L., Flitman, S., Michel, B.F., Boada, M., Frank, A., Hock, C. (2003) Subacute meningoencephalitis in a subset of patients with AD after Abeta42 immunization. Neurology, 61, 46-54.

[60] Papasozomenos, Sch., Shanavas, A. (2002) Testosterone prevents the heat shock-induced overactivation of glycogen synthase kinase- 3 beta but not of cyclin-dependent kinase 5 and c-Jun NH2-terminal kinase and concomitantly abolishes hyperphosphorylation of tau: implications for Alzheimer's disease. Proc. Natl. Acad. Sci. USA, 99, 1140-5.

[61] Permanne, B., Adessi, C., Saborio, G.P., Fraga, S., Frossard, M.J.(2002) Reduction of amyloid load and cerebral damage in a transgenic mouse model of Alzheimer's disease by treatment with a beta-sheet breaker peptide. FASEB J., 16, 860-2.

[62] Petit, A., Bihel, F., Alves da Costa, C., Pourquie', O., Kraus, J.L., Checler, F. (2001) New protease inhibitors prevent $\gamma$-secretase-mediated A $\beta 40 / 42$ production without affecting Notch cleavage. Nat. Cell. Biol., 3, 507-511.

[63] Pfeifer, M., Boncristiano, S., Bondolfi, L., Stalder, A., Deller, T., Staufenbiel, M., Mathews, P.M., Jucker, M. (2002) Cerebral hemorrhage after passive anti-Abeta mmunotherapy. Science, 298, 1379.

[64] Postina, R., Schroedev, A., Dewachter, I., Bohl, J., Schmitt, U., Kojro, E. (2004) A disintegrin-metalloproteinase prevents amyloid plaque formation and hippocampal defects in an Alzheimer disease mouse model. J. Clin. Investig., 13, 1384-1392.

[65] Potkin, S.G., Anand, R., Fleming, K. (2001) Brain metabolic and clinica effects of rivastigmine in Alzheimer's disease. Int. J. Neuropsychopharmacol., 4, 223-30.

[66] Pratico, D., Clark, C.M., Liun, F., Rokach, J., Lee, V.Y., Trojanowski, J.Q. (2002) Increase of brain oxidative stress in mild cognitive impairment: a possible predictor of Alzheimer disease. Arch. Neurol., 59, 1475

[67] Qu, B., Rosenberg, R.N., Li, L., Boyer, P.J., Johnston, S.A. (2004) Gene vaccination to bias the immune response to amyloid-beta peptide as therapy for Alzheimer disease. Arch. Neurol., 61, 1859-64.

[68] Rachakonda, V., Pan, T.H., Le, W.D. (2004) Biomarkers of neurodegenerative disorders: How good are they? Cell. Res., 14, 349-360.

[69] Rezai-zadeh, K., Shytle, D., Sun, N., Mori, T., Hou, H., Jeanniton, D., Ehrhart, J., Townsend, K., Zeng, J., Morgan, D., Hardy, J., Town, T., Tan, J. (2005) Green tea epigallocatechin-3-gallate (EGCG) modulates amyloid precursor protein cleavage and reduces cerebral amyloidosis in Alzheimer transgenic mice. J. Neurosci., 25, 8807-14.

[70] Rockwood, K., Mintzer, J., Truyen, L., Wessel, T., Wilkinson, D. (2001) Effects of a flexible galantamine dose in Alzheimer' s disease: a randomized, controlled trial. J. Neurol. Neurosurg. Psychiatry, 71, 589-95.

[71] Rozemuller, A.J., van Gool, W.A., Eikelenboom, P. (2005) The neuroinflammatory response in plaques and amyloid angiopathy in Alzheimer's dis- 
ease: therapeutic implications. Curr. Drug Targets CNS. Neurol. Disord., 4, 223-33.

[72] Ryder, J., Su, Y., Liu, F., Li, B., Zhou, Y., Ni, B. (2003) Divergent roles of GSK 3 and CDK5 in APP processing. Biochem. Biophys. Res. Commun., 312, 922-9.

[73] Schenk, D., Barbour, R., Dunn, W., Gordon, G., Grajeda, H., Guido, T., Hu, K., Huang, J., Johnson-Wood, K., Khan, K. (1999) Immunization with amyloid-beta attenuates Alzheimer-disease-like pathology in the PDAPP mouse. Nature, 400, 173-177.

[74] Siemer, E., Skinner, M., Dean, R.A., Conzales, C., Satterwhite, J., Farlow, M., Ness, D., May, P.C. (2005) Safety, tolerability, and changes in amyloid beta concentrations after administration of a gamma-secretase inhibitor in volunteers. Clin. Neuropharmacol., 28, 126-32.

[75] Sigurdsson, E.M., Knudsen, E., Asuni, A., Fitzer-Attas, C., Sage, D., Quartermain, D., Goni, F., Frangione, B., Wisniewski, T. (2004) An attenuated immune response is sufficient to enhance cognition in an Alzheimer's disease mouse model immunized with amyloid-beta derivatives. J. Neurosci., 24, 6277-82.

[76] Sigurdsson, E.M., Scholtzova, H., Mehta, P.D., Frangione, B., Wisniewski, T. (2001) Immunization with a nontoxic/nonfibrillar amyloid-beta homologous peptide reduces Alzheimer's disease-associated pathology in transgenic mice. Am. J. Pathol., 159, 439-47.

[77] Singer, O., Marr, R.A., Rockenstein, E., Crews, L., Coufal, N.G., Gage, F.H., Verma, I.M., Masliah, E. (2005) Targeting $\beta$-secretase1 with siRNAs ameliorates Alzheimer disease neuropathology in a transgenic model. Nat. Neurosci., 8, 1343-1349.

[78] Shah, S., Lee, S.F., Tabuchi, K., Hao, Y.H., Yu, C., LaPlant, Q., Ball, H., Sudhof, T., Yu, G. (2005) Nicastrin Functions as a $\gamma$-Secretase-Substrate Receptor. Cell, 122, 435-447.

[79] Soto, C., Kindy, M.S., Baumann, M., Frangione, B. (1996) Inhibition of Alzheimer's amyloidosis by peptides that prevent beta-sheet conformation. Biochem. Biophys. Res. Commun., 226, 672-680.

[80] Soto, C., Sigurdsson, E.M., Morelli, L., Kumar, R.A., Castano, E.M., Frangione, B. (1998) Beta-sheet breaker peptides inhibit fibrillogenesis in a rat brain model of amyloidosis: implications for Alzheimer's therapy. Nat. Med., 4, 822-826.

[81] Suh, Y.H., Checler, F. (2002) Amyloid precursor protein, presenilins, and $\alpha-$ synuclein: molecular pathogenesis and pharmacological applications in Alzheimer's disease. Pharmacol. Rev., 54, 469-525.

[82] Tanne, J.H. (2005) Activating stem cells may treat Alzheimer's. BMJ, 330, 622.

[83] Thinakaran, G., Parent, A.T. (2004) Identification of the role of presenilins beyond Alzheimer's disease. Pharmacol. Res., 50, 411-8.
[84] Troy, C.M., Rabacchi, S.A., Hohl, J.B., Angelastro, J.M., Greene, L.A., Shelanski, M.L. (2001) Death in the balance: alternative participation of the caspase-2 and -9 pathways in neuronal death induced by nerve growth factor deprivation. J. Neurosci., 21, 5007-5016.

[85] Tuszynski, M.H., Roberts, J., Senut, M.C., U, H.S., Gage, F.H. (1996) Gene therapy in the adult primate brain: intraparenchymal grafts of cells genetically modified to produce nerve growth factor prevent cholinergic neuronal degeneration. Gene Ther., 3, 305-14.

[86] Tuszynski, M.H., Thal, L., Pay, M., Salmon, D.P., U, H.S., Bakay, R. (2005) A phase 1 clinical trial of nerve growth factor gene therapy for Alzheimer disease. Nat. Med., 11, 551-5.

[87] Tuszynski, M.H., Thal, L., U, H.S., Pay, M.M., Blesch, A., Conner, J., Vahlsing, H.L. (2002) Nerve growth factor gene therapy for Alzheimer's disease. J. Mol. Neurosci., 19, 207.

[88] Tyszkiewicz, J.P., Yan, Z. (2005) beta-Amyloid peptides impair PKCdependent functions of metabotropic glutamate receptors in prefrontal cortical neurons. J. Neurophysiol., 93, 3102-11.

[89] Van der Schyf, C.J., Gal, S., Geldenhuys, W.J., Youdim, M.B. (2006) Multifunctional neuroprotective drugs targeting monoamine oxidase inhibition, iron chelation, adenosine receptors, and cholinergic and glutamatergic action for neurodegenerative diseases. Expert Opin. Investig. Drugs, 15(8), 873-86.

[90] Walker, E.S., Martinez, M., Brunkan, A.L., Goate, A. (2005) Presenilin 2 familial Alzheimer's disease mutations result in partial loss of function and dramatic changes in Abeta 42/40 ratios. J. Neurochem., 92, 294-301.

[91] Wang, Q.H., Xu, R.X. (2005) Transplantation of cholinergic neural stem cells in a mouse model of Alzheimer's disease. Chin. Med. J., 118, 508-511.

[92] Weihofen, A., Lemberg, M.K., Friedmann, E., Rueeger, H., Schmitz, A. Paganetti, P., Rovelli, G., Martoglio, B. (2003) Targeting presenilin-type aspartic protease signal peptide peptidase with $\gamma$-secretase inhibitors. J. Biol. Chem., 278, 16528-16533.

[93] Weiner, H.L., Lemere, C.A., Maron, R., Spooner, E.T., Grenfell, T.J., Mori, C., Issazadeh, S., Hancock, W.W., Selkoe, D.J. (2000) Nasal administration of amyloid-beta peptide decreases cerebral amyloid burden in a mouse mode of Alzheimer's disease. Ann. Neurol., 48, 567-79.

[94] Weksler, M.E. (2004) The immunotherapy of Alzheimer's disease. Immun Ageing, 1, 2 .

[95] Yogev-Falach, M., Bar-Am, O., Amit, T., Youdim, M.B. (2006) The multifunctional neuroprotective anti-Alzheimer/ anti-Parkinson drug ladostigil (TV3326) regulates holo-APP translation and processing. FASEB J., 20, 2177-2179.

[96] Youdim, M.B., Amit, T., Bar-Am, O., Yogev-Falach, M. (2006) Implications of co-morbidity for etiology and treatment of neurodegenerative diseases with multifunctional neuroprotective-neurorescue drugs; ladostigil. Neurotox. Res., 10(2), 1-11. 